\title{
DIPLOMATIC RELATIONS AND ECONOMIC COOPERATION BETWEEN CAMEROON AND ITALY
}

\author{
JONAS AWANDEM NKENGAFAC \\ Masters of Science in Political Science and International Relations, Department of Political Science and \\ International Relations, Istanbul Aydin University, Istanbul, Turkey
}

This paper is submitted as a partial fulfillment of the requirements for the award of a Master of Science in Political Science and International Relations.

\begin{abstract}
This study is an empirical review of the relations that Cameroon and Italy have had for the last three decades. The study is inquisitive to understand why these two countries have been so apt to get closer and closer and how impactful that will be to the entire Gulf of Guinea where Cameroon occupies a pivotal position. The study starts by looking at the theories of liberalism and neoliberalism which are both used as the foundation to understand the domestic and foreign policies of Cameroon vis-à-vis this economic cooperation with Italy. More so, the study follows to study and discuss the different levels by which Cameroon and Italy have entreated economic relations and how imperative these economic relations are to both countries. Lastly, the study concludes by making strong recommendations that are meant to help Cameroon wake up from where it slumbers and where policy amendments need to be done.
\end{abstract}

Key words: Liberalism, neoliberalism

DOI: $10.7176 / \mathrm{JAAS} / 56-10$

Publication date:June $30^{\text {th }} 2019$

Definition of key terms

\section{Liberalism}

Chau (2009) highlights that liberalism is the study that elevates the individual above everything other thing in the state and gives him a distinct position. It centers holds on individualism and liberty. Notwithstanding it reiterates its stance that the state should promote the development and progress of the individual and allow him to reach any level he desires. To achieve this liberty is highly indispensable (Chau, 2009).

Melleuish (2009 cited in Chau, 2009) adds that liberalism has two fundamental principles which are individualism and liberty. He goes ahead to add that the foundational thought of liberalism in political science remains that governments should not interfere with the private lives of citizens except on very extreme situations.

From the definitions above it can be seen that they all stress on human rights, personal property rights, freedom and liberty. Therefore, following the arguments of these scholars and many others, liberalism is all about the welfare of the citizens and it's made possible following the domestic policies of their state. Sometimes, states might enter partnerships and other cooperation with other states because they seek better opportunities to better the lives of their citizens back home. So, at the end of the day, liberalism worries much about the welfare of the human subject within well-defined territorial strata.

\section{$\underline{\text { Neoliberalism }}$}

Havey (Harvey, 2005 cited in Thorsen and Lie, 2010) defines neoliberalism as "an economic theory which struggles to institutionalize and liberate the human entrepreneurial rights through free market, ensure a strong property rights and assure private property rights and free trade". He continues that though neoliberalism somewhat sounds like liberalism, it's actually a revised form of the latter and seeks in broader terms to explain the deep needs 
of the state in developing both the economic sectors and the human capital which is seen as the driving locomotive by which the economy takes its aroma.

Though Blomgren (Anna-Maria Blomgren, 1997 cited Thorsen and Lie, 2010) doesn't differ much from Havey (2005) cited above she adds that "neoliberalism is much of a philosophical thought which turns to give priority to individual freedom and preaches individual property rights (Blomgren, 1997). Somehow she insists that there might not be an easy identification of a linear line which helps one to study and fully comprehend it to be a homogenous philosophy. For her, there are many ethical premises and some normative conclusions which overlap in its full study and analysis.

It's important to make it clear that though the international community has become highly decompartmentalised that is having many bodies and voices that can speak and proxy for people and states, the foremost actor of the international community is the state. This is because all intergovernmental organizations, multinational companies, NGOs and civil society groups cannot match up with the power of sovereignty that states claim and usurp. More so, these international organizations and regimes all gain their foundations and power from states that formed them and that can decide to do away with them.

\section{The concept of liberalism}

Gray (2009 cited in Chau, 2009) adds that the fundamental role of liberalism simply is to provide equal rights; opportunities and privileges to everyone and these rights are political and economic rights. This means states must ensure their citizens are free to exercise their rights as much as they desire and require. More so, political suppression and exclusion must be avoided as this could cause an insurgency and a reason why some countries like Congo, South Sudan, the Central African Republic and Cameroon are suffering from civil wars. The disrespect of these political and economic rights is good enough to radicalize citizens who might use any opportunity to start a rebellion. Therefore, it's of great necessity that humans the world over must be treated the same and provided with the same opportunities regardless of cultures, race and economic status and this is the sole responsibility of the state.

So, for countries especially underdeveloped countries to make an impact on the international scene, they must spend more on industrialization and on bettering their social welfare so that their citizens feel at home. Secondly, though security is an important factor and one that requires a lot of contingency, states must nonetheless, spend more on economic development rather than military welfare. For realists it might be necessary to spend much on military might which for them is a good way to protect the country from foreign attack. However, contrary to realist arguments they insist that instead, states thrive for better relations with their neighbors and consequently might even join international institutions where they have greater prospects to make absolute gains. They add that it might be better to further, adjust to this claim by looking at the three levels of analysis proposed by liberalism by which state behavior can be studied and understood. They include the individual, state and international analysis.

Rousseau and Walker (2012) add that liberalism in its plight to explain human and state relations firstly, does not dodge the democratic peace theory which states that democracies do not go to war. Secondly, they hold the assertion that democratic states behave differently and most times independently support each other in mutual ways. Contrary to realism which preaches force and coercion liberalism sees cooperation as a means to end the violence. As a matter of fact, Rousseau and Walker (2012) identify three potential claims of liberalism which are:

Firstly, democracy reduces military spending, secondly, economic interdependence reduces military conflict and lastly, international institutions reduce military conflict. Unlike realism which advocates for power at all cost, liberalism is seen as the good guy who believes that good human-state relations and policies will lead to incentives of democracy which in the short run, will have a tremendous effect on the state's foreign policy and balance in the international system.

\section{The Concept of neoliberalism}

While liberalism looks at the appropriation of the individual who is considered important and at the center of interest, neoliberalism in international relations looks at it from a different perspective. According to Thompson (2005) neoliberalism in international relations has an economic prerogative that is to say it strictly looks at the dissipation of capital. Furthermore, it could be said that in some respects neoliberalism is an advocate of capitalism because it looks at the flow of means of production and how impactful they could be not only for domestic consumption but also for the international community (Wikan, 2015). However, there are many who think that 
liaising capitalism with economic neoliberalism should explain the way both concepts are managed for the actualization of economic relations between states Wikan (2015, cited Litonjua 2008). However, Thompson (2005) reiterates that using the word capital in his explanation doesn't implicitly imply economics or monetary transactions. Instead, he warns that it simply means the organizing principle of modern society.

This study is of the opinion that amid this debate, it doesn't cancel the fact that most scholars are of the opinion that pronouncing the word neoliberalism simply brings international market economics on the discussion table. Similarly, how states approach this international trade depends on their attitudes which could be qualified in political terms as their foreign policy and also on the systemic flow of political and cultural relations in the international system. For Mammadov and Hassanov (2016) neoliberalism is the seed of a struggling political agenda which seeks to expand its intent for domination which at the same time suffers an impending class struggle between societies. The foremost reason for this class struggle might go back to Thompson (2005) who sees neoliberalism as a capitalist doctrine with a global expansionist agenda. And the best possible way to accentuate this policy is to beef up factors of production because the more the production, the higher the possibility to gain new grounds, markets and territories. Thorson and Lie (2010) agree that power and wealth are constantly on the increase and this is demonstrated through the rapid spread of multinational companies which are backed by sometimes harsh political and economic decisions for the achievement of the ultimate goal. Thorson and Lie (2010) add that neoliberalism is a revival of Adam Smith's capitalist economic proposals which entail strong economic and policy makings.

On this note, this study would like to state that considering the multi polarity nature of the world today, no state will achieve anything economically or politically if they adopt the policy of force. This is because globalization is stretching through countries and exposing many grounds of interactions which would otherwise not be possible if force is enacted. While neoliberalism in international relations asserts that states should go after their absolute gains rather than seek relative gains (Jervis, 1999), Whyte (2012, cited Keohane and Nye, 2001) on the other hand argue that interdependence, particularly economic interdependence, is now an important feature of world politics. On these bases of cooperation, many states joined under the canopy of institutions such as the IMF, the World Bank, the United Nations, etc. work together to find ways that would better their lives together.

According to Simon (2007) states can cooperate among themselves in an equitable way through the help of international institutions which facilitate relations between them and by also providing them with all the information they need to set themselves up. The World Health Organization (2018) adds that "cooperation among countries can be an effective tool to strengthen, share and accelerate health development within countries and across regions". Where countries cannot help themselves international institutions come in to help them solve issues that have transgressed political boundaries.

Neoliberalism asserts that anarchy could be an impediment and limiting factor but international institutions help states overcome many of these boundaries (Simon, 2007). Mir (2014) is of the opinion that anarchy is such a limiting factor which is capable of creating chaos among states even when they share similar goals and interests. Therefore, the work of international institutions is much because they have to make sure that the personal interests of states, which cannot be limited, do not overtly interfere to the detriment of cooperating with other states. Though realism is for this fact and encourages states to take cooperation as a chance to gain maximum power (Whyte, 2012), neoliberalism instead fights hard to limit it for the benefit of all. Simon (2007) thinks that anarchy can be tackled through a conglomerate of good will actors who abandon their selfish interests. Moreover, the creation of these institutions ascertains that anarchy can be filled up and later dissolved.

Neoliberalism assumes that human beings have the abilities to lead and can be trusted in their leadership (Simon, 2007). Unlike realism which does not trust human ability but instead suspects that it might use it for coercion (Whyte, 2012), neoliberalism is nothing without it. This is because though institutions are the agents who foster collaboration between states, they are nonetheless, powered by human brains. For this reason they stand trust worthy and walk tall in all state and interstate endeavors. Above it was discussed that liberalism advocates for the development of human beings. Therefore, the position of humans here is simply an eloquent testimony of the developments they have undergone and the many investments made in them by their states such that they are able to man these many institutions and under the most challenging moments. This study sees it that neoliberalism and international institutions give man the distinct ability to maintain his innovating, developmental processes.

Collaboration is very difficult especially seeing the fact that no two states might have the same troubles at least, on the same scale. However, states after weighing their cost and benefit analysis will certainly prefer to join in than remain isolated Whyte (2012 cited in Keohane, 1984). A vital ingredient that mostly generates strive and tension among states in the international system is greed and selfishness and might be tempted to use force in some 
cases to achieve their objectives. To limit this before its spill overs create more problems than needed, institutions consider the power disparity existing among states and try to balance them. However, it's difficult to control or completely reduce the power of a state thoughtless of controlling its behavior. As a matter of fact, states simply look out for their own interests but will in many cases prefer collaboration rather than war or coercion Whyte (2012 cited in Mearsheimer, 1995).

Gains are of paramount imperative in cooperation and many states might fear to be at the losing end. Realists think that this is one of those decisive moments that momentarily pushes states to question the sharing of the spoils in view. In fact Waltz (Waltz, 1979 cited in Whyte, 2012) argues, under global anarchy, "when faced with the possibility of cooperating for mutual gains, states that feel insecure must ask how the gain will be divided". There is a strong tendency for states to claim all if they can and though that is not usually the case, it's actually a possibility. Moreover, it can be argued that states pursue relative gains and will not hesitate to claim the spoils if the opportunity presents itself. However, Mastanduno (1991 cited in Whyte, 2012) frowns at relative gains and suggests that though relative gains sound appealing, they can nonetheless, be destructive as they are conducive to the twin evils of protectionism and nationalism". Therefore, states will go for mutual gains or absolute gains and will even prefer to engage in bilateral partnerships that will last for long and produce longer absolute gains with their partners.

On this regards institutions also must strive to create independent policies and mechanisms that are free from foreign interferences and universal in approach so that no state feels victimized and trampled upon. Neoliberalism fosters institutional performance in this regards and seeks for ways by which internal systems can be designed with all inclusive principles by which the collaboration between states will be efficient, meaningful and lasing (Simon, 2007).

\section{Economic}

For over fifteen years now, Cameroon in defiance of the depleting "Accord de Cooperation or Accord of Cooperation" it signed with France prior to independence in 1959, which made France it's one and only economic partner, it has been on an adventure to diversify its economic partners. This diversification has ushered in the Russians, Chinese, Italians, Vietnamese, Brazilians, and South Koreans who through agreements are helping Cameroon in key areas of its economic development and growth. On February 2017 an Economic Forum that assembled investors and entrepreneurs in Cameroon for the Small and Medium Sized Enterprises dubbed PROMOTE and usually under the auspices of the Prime Minister of the Republic, exposed Cameroon's investment potentials and encouraged Italian investors to consider Cameroon as the place to invest (Business in Cameroon, 2017). This first contact with the Italian business class was aimed at establishing partnerships but a second Economic Forum held in Rome and chaired by Cameroon's president Paul Biya, brought many stunning revelations that might have really convinced many Italian investors to find their way to Cameroon. Business in Cameroon (2017) explains that following these Cameroon-Italian joint meetings, Cameroon specifically desires investors in the areas of housing, agriculture, logging, skin and leather and marble production. Fortunately, Italy has companies that are well advanced in these sectors and a strong factor that made Cameroon to seek for their interests. As regards to housing the two countries signed "the Memorandum of Understanding between the National School of Public Works and the University of Padua. The Memorandum of Understanding between the Ministry of Housing and Urban Development and the Department of Civil Engineering, Architectural and Environmental at the same University, for the promotion of sustainable urban development in Cameroon" (CameroonWeb, 2016). In his address Paul Biya reiterated to his Italian counterparts that Cameroon "has a healthy business climate regardless of some irregularities that his government is working on. Secondly, Cameroon has a stable debt" so whoever invests in Cameroon he stressed, should in the short run become one of "Cameroon's top business partners" (Business in Cameroon, 2017). This came after it was officially announced that "Italy has canceled Cameroon's debt of CFA99.3 billion stretched over the past ten years" (APA News, 2017). The reason for this cancellation was when Cameroon reached the completion point of Heavily Indebted Poor Country (HIPIC) (World Bank, 2018).

\section{Infrastructure}

Cameroon suffers heavily from mismanagement, embezzlement, corruption and the misappropriation of state funds which could have raised the country's infrastructural potential high. It's shameful to think that fifty years after independence Cameroon has only over $50.000 \mathrm{kms}$ of road network with over $5.000 \mathrm{~km}$ tarred (Business in Cameroon, 2019). Shamefully, only about $10 \%$ of Cameroon's roads are tarred with the greater majority being untarred. The government aims at increasing the percentage to up to $17 \%$ and with over $8.500 \mathrm{~km}$ by 2020 . While this is only one of the sectors that suffer infrastructural hardships, the entire nation struggles with poor 
infrastructure and cold be one of the reasons why Cameroon tirelessly seeks foreign funding to meet up. The infrastructural disgrace of Cameroon didn't go unnoticed and was detrimental to Cameroon's privileged hosting rights of the African Nations Cup for 2019. Alas, Cameroon's hosting rights of the African Cup of Nations before it was stripped off the rights to host the prestigious African soccer tournament, dubbed for 2019 brought open doors for potential investors who flooded the country all trying to win a share of their contracts. For Cameroon, this was an opportunity to step up the country's infrastructure and make the country easy and comfortable for Cameroonians and all expatriates who live therein. Though many countries wrestled hard to have an investment place in Cameroon the Italians had much to rest about.

The Italians were on a pacific highway and needed not stress too much because the economic agreements they had signed with Cameroon following the cancellation of Cameroon's debts (APA News, 2017) as mentioned above, gave them a leeway. More so, the Italian construction company, Piccini, won the contract to build Cameroon's biggest football stadium called Paul Biya stadium situated in the Olembe neighborhood in the outskirts of Yaoundé, the nation's capital (Business in Cameroon, 2016, p. 13). This study understands that this company was chosen following its success in constructing one of the Italian stadiums where the 1990 World Cup was played and where Cameroon made a stunning performance by beating Argentina 1 goal to nil in the opening game and becoming the first African nation to ever reach the quarter finals of the FIFA World Cup. In order to show their support and concern for the success of completing this project and preserving Cameroon's glory as the Brazil of Africa, the newly appointed Ambassador of Italy to Cameroon, Marco Romiti, paid a courtesy visit to the Cameroonian Minister of Sports and Physical Education (Mosima, 2017). Mosima (2017) testified that his visit affirmed Italy's obligation and resolve to accompany Cameroon through the frivolous paths of preparing for the competition. The Presidency of Cameroon (2017) adds that bilateral agreements with Italians reveal that they also have to construct over 10.000 residential houses in Cameroon. And this is only one of the many projects that the government of Cameroon has in view of its 3 years emergence goals for the nation. Amid these, there are many other projects that require funding some of which are the tarring of highways, construction of new airports and the rehabilitation of already existing ones, the construction of the Cameroon-Chad railway which is still not complete (Presidency of Cameroon, 2017). So, the economic relations between Cameroon and Italy carry a heavy envelope which according to the Italian president satisfies Italy's interests in the region. It behooves this study to add that before 2006, Cameroon didn't quite feature in Italy's list of potential partners in Africa. However, following many fruitful exchanges, the Italians see a potential in Cameroon and want to help Cameroon develop its economy so that less Africans will cross the Mediterranean to go to Europe. For the Italians it's not just money and economics but also an issue of national security. More so, the visit was a diplomatic move aimed at solidifying the cooperation between the Ministries of Sports of the two countries. Unfortunately, the hosting rights of the competition have been stripped off from Cameroon by the Confederation of African Football because the Confederation of African Football complained that Cameroon despite having been given five years to prepare for this competition, Cameroon is sure not to be ready in ten years seeing that the competition begins in June 2019 but basic infrastructures such as roads, hotels and hospitals are nowhere to be found (Kazeem, 2018). However, work continues and the company is determined to complete the stadium by the expected deadline.

\section{References}

APA News (2017), "Italy writes off CFA100 billion Cameroon debts", website viewed at: $<$ http://apanews.net/en/news/italy-writes-off-cfa100-billion-cameroon-debt $>$

Business in Cameroon (2019c), "Over a hundred deaths on Cameroonian roads in two months", website viewed at: $<$ https://www.businessincameroon.com/transport/0109-7362-over-a-hundred-deaths-on-cameroonianroads-in-two-months $>$

Chau, R., (2009), "Liberalism: A Political Philosophy", website viewed at: $<$ https://www.mannkal.org/downloads/scholars/liberalism.pdf $>$

CameroonWeb (2016), “Italy canceled Cameroon's debt", webpage viewed at: $<$ https://www.camerounweb.com/CameroonHomePage/business/Italy-canceled-Cameroon-s-debt$\underline{363180>}$

Kazeem, J., (2018), “Cameroon has been stripped of rights to host Africa’s biggest sports event”, Quartz, website viewed at: website viewed at: $<$ https://qz.com/africa/1481025/afcon-cameroon-lose-soccer-hosting-rights$\underline{\text { morocco-likely/> }}$ 
Havey, D., (2005), “A Brief History of Neoliberalism by David Harvey, Oxford University Press, pp. 256

Mosima, E., (2017), "Cameroon: Italy-Cameroon - Sport Relations Strengthened”, allAfrica, webpage viewed at: $<$ https://allafrica.com/stories/201712180475.html $>$

Presidency of Cameroon (2017a), "State Visit of H.E. Paul BIYA, President of the Republic of Cameroon, to Italy", pp. 1-43, website viewed at: $<$ https://www.prc.cm/files/54/7e/56/17e8bfd417f2683c87a7bea3e522bbcc.pdf7>

Rousseau, D. L, Walker, T. C., (2012), "Handbook of Security studies", website viewed at: $<$ https://www.gvsu.edu/cms4/asset/54A33349-DDB5-912252D039391EF8BB6C/rousseau walker liberalism_10.pdf $>$

Simon, Sheldon W., (2007), "Realism and neoliberalism: International relations theory and Southeast Asian security", doi: 10.1080/09512749508719123, The Pacific Review

Thorsen, E. D., Lie, A. (2010), "What is Neoliberalism? University of Oslo, p. 1-21

Thompson (2005), "The World According to David Harvey", A Journal of Modern Society \& Culture, website viewed at: http://rebels-library.org/files/d3Thompson-1.pdf

Jervis, R., (1999), "Realism, Neoliberalism, and Cooperation”, International Security, Vol. 24, No. 1, pp. 42-63, website viewed at: file://C:/Users/B/Downloads/2539347.pdf

Whyte, A., (2012), "Neorealism and neoliberal institutionalism: born of the same approach?, E-International Relations Student, website viewed at: $<$ https://www.e-ir.info/2012/06/11/neorealism-and-neoliberalinstitutionalism-born-of-the-same-approach/> 